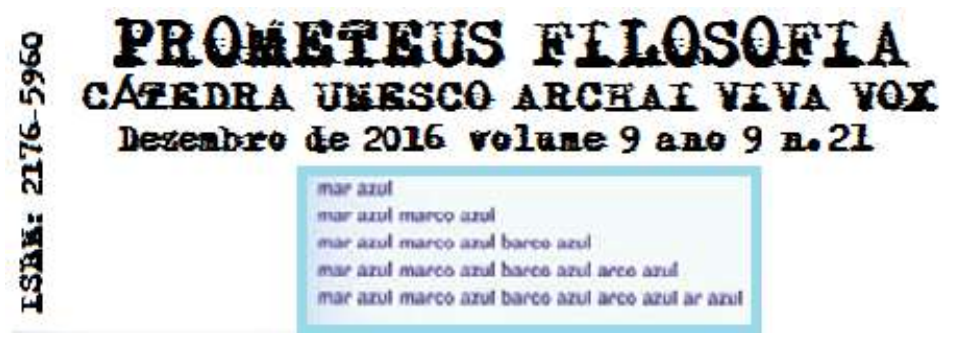

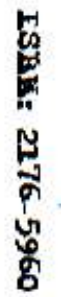

\title{
A ESCRITA HERACLÍTICA DE FERREIRA GULLAR ${ }^{1}$
}

\begin{abstract}
RESUMO: Em Vanguarda e Subdesenvolvimento, Ferreira Gullar, partindo da dialética marxista e da noção de obra aberta de Umberto Eco, chega a uma concepção de poesia como "revelação da atualidade do atual". Essa revelação não pode ser abstrata, mas deve se originar da situação histórica, social e política na qual vive o poeta. Isso nos faz lembrar um aforismo de Heráclito que nos diz que "Dando ouvidos não a mim, mas ao logos, é avisado concordar que todas as coisas são uma". Isto é, embora se reconheça que todas as coisas estão em relação umas com as outras, perfazendo uma unidade concreta absoluta, o ser humano é incapaz de experienciar tal unidade. Caberá ao poeta atingir a universalidade através da expressão de suas experiências concretas, e não tentar alcançar um universal "artificial", produzindo um falso discurso.
\end{abstract}

PALAVRAS-CHAVE: Heráclito. Fluxo. Poesia. Ferreira Gullar.

ABSTRACT: In Vanguarda e Subdesenvolvimento, Ferreira Gullar, starting from Marxist dialectics and Umberto Eco's notion of open work of art, arrives at a conception of poetry as "revelation of the presentness of the present". This revelation cannot be abstract, but should begin at the historical, social and political situation in which the poet lives. In this sense, remembering an aphorism of Heraclitus which says that "Hearing not me but the logos, we must agree that everything is one", we should say that, though recognizing that all things are related one to another, making a concrete unity, human being is unable to experience such unity. Is up to the poet reach out this universality expressing his own concrete experiences, and not trying to attain an "artificial" universal, constructing a false discourse.

KEYWORDS: Heraclitus. Flux. Poetry. Ferreira Gullar.

\footnotetext{
${ }^{1}$ Publicado originalmente em AISTHE, volume 7, 2011.
} 
Em Vanguarda e Sub-desenvolvimento, Ferreira Gullar, partindo da dialética marxista e da noção de obra aberta de Umberto Eco, chega a uma concepção de poesia como "revelação da atualidade do atual":

Revelar a atualidade do atual é a função primeira da poesia, função essa que a formulação idealista do fenômeno poético procura identificar com a experiência ontológica metafísica. Quando se atribui ao poeta a missão órfica de "nomear as coisas" não se está dizendo, na verdade, senão que ele, ao falar delas, revela-lhes a atualidade, a condição histórica: tira-as da sombra, do limbo, para mostrá-las, reais, concretas, aos homens. Essa é a razão por que o discurso que não carrega em seu cerne uma experiência concreta a comunicar, nada revela, não é poesia, e, a rigor, é um falso discurso. O poeta, portanto, não cria, não inventa, mas apenas diz, mostra o existente existindo, e isso só o consegue por revelar, simultaneamente, o que existe enquanto experiência particular e enquanto experiência geral do homem. E tal fato se dá sempre em situações determinadas, históricas [...] A consciência concretatambém poética - das coisas é a consciência que eu tenho delas aqui, neste momento - deste aqui no espaço do mundo, deste momento no momento global da realidade, em suma, das relações históricas, em seu mais amplo sentido, que ligam cada instante de nossa existência à existência de todo o real, de todas as coisas e de todos os homens. (1978, p.53)

Essa revelação não pode ser abstrata, mas deve partir da concretude experienciada, da situação histórica, social e política na qual vive o poeta. Isso nos faz lembrar um aforismo de Heráclito que nos diz que "Dando ouvidos não a mim, mas ao logos, é avisado concordar que todas as coisas são uma" (Kirk-Raven, 1994, p.193), isto é, embora se reconheça que todas as coisas estão em relação umas com as outras, perfazendo uma unidade concreta absoluta, a condição humana se insere existencialmente sempre no viés relativo, sendo, portanto, incapaz de experienciar aquela unidade. Caberá ao poeta, como diz Gullar, atingir a universalidade através da expressão da individualidade, de suas experiências concretas, e não, pretendendo elevarse sobre estas, tentar alcançar um universal "artificial", produzindo um falso discurso.

A poesia de Gullar procura dar cabo dessa tarefa, sendo nela constantes as imagens do fluxo, que é expresso de diversas formas, entre as quais a imagem 
heraclítica e dinâmica do fogo constituinte de todas as coisas. Assim, no poema "As Peras", de A luta Corporal, nos diz o poeta: "As peras, no prato,/ apodrecem./ O relógio, sobre elas/mede/ a sua morte?/ [...] Oh as peras cansaram-se/ de suas formas e de/ sua doçura! As peras, concluídas, gastam-se no/ fulgor de estarem prontas / para nada" (2007, p. 36). Gullar, a partir da concretude que tem diante de si ou sobre a qual reflete, o prato de peras que apodrecem, universaliza o fato do fluxo de forma intensa: "Tudo é cansaço/ de si. As peras se consomem/ no seu doirado/ sossego. As flores, no canteiro/ diário, ardem,/ ardem, em vermelhas e azuis. Tudo/ desliza e está só". O mesmo tema é retomado no poema "Frutas", de O Vil Metal:

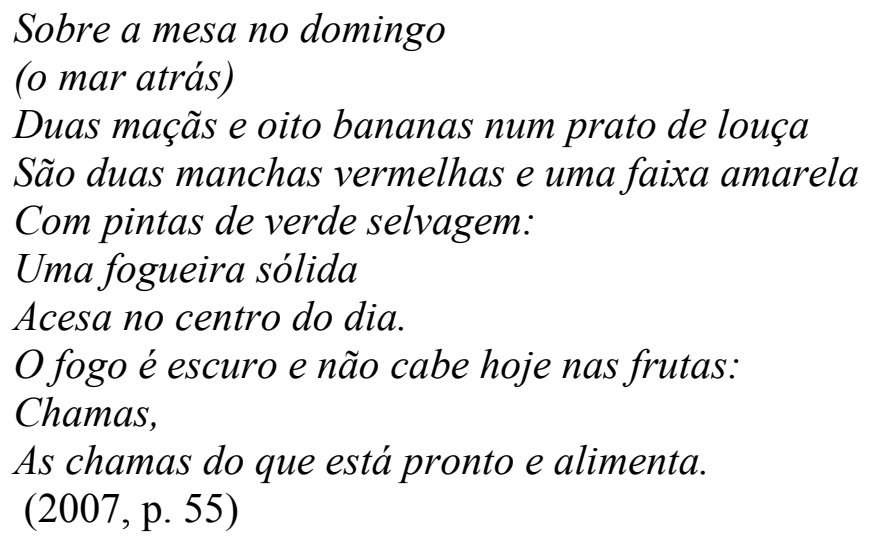

No poema "Dentro da Noite Veloz", do livro de mesmo nome, o poeta nos diz, reafirmando o fluxo através da frutífera imagem: "A vida muda como a cor dos frutos/ lentamente/ e para sempre/ A vida muda como a flor em fruto/ velozmente" (2007, p. 100). Em Na vertigem do dia, tal reflexão é retomada, no poema "Bananas Podres":

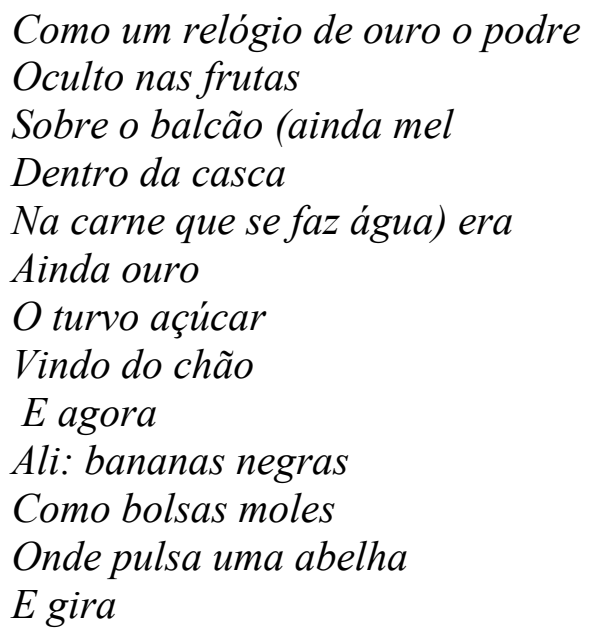




\section{E gira ponteiro no universo dourado (parte mínima da tarde) \\ Em abril \\ Enquanto vivemos. (2007, p. 155)}

O poeta, no mesmo poema, reflete sobre a relação entre os frutos apodrecidos, as demais coisas e o distante o mar: "Que tem a ver o mar/ com estas bananas/ já manchadas de morte?/ [...] Que tem a ver o mar/ com esse marulho/ de águas sujas/ fervendo nas bananas? Com estas vozes que falam de vizinhos,/ de bundas, de cachaça?". E Gullar conclui com a afirmação do refulgente pulsar de tudo: "tanto marulha o mar quanto a floresta/ tanto/ fulgura o mel da tarde/ - o podre fogo-/ como fulge/ a esmeralda de água/ que se foi”.

No poema "Omissão", de Barulhos, o poeta se indaga: que relação teria a reflexão sobre frutos que apodrecem e as contradições da sociedade: "Não é estranho?/ por que então/ mergulho nessa minicatástrofe/ doméstica / de frutas que morrem?". A resposta vem a seguir:

É compreensível que tua pele se ligue à pele dessas frutas que apodrecem

pois ali

há uma intensificação do espaço, das forças

que trabalham dentro da polpa

(enferrujando na casca/ a cor/ em nódoas negras)

[...] bananas apodreceram/ subvertendo a ordem da história humana. (2007, p. 184)

O espetáculo da putrefação das frutas é uma imagem dos processos nos quais se inserem a realidade humana e seus valores, todos sujeitos, ou melhor, condenados à putrefação, à subversão, à transformação: "e é bom morrer/ no teatro/ vendo morrer/ peras ardendo/ na sua própria fúria/ e urinando/ e afundando em si mesmas/ a converterse em mijo, a pêra, a banana ou o que seja".

Para o poeta, alcançar o universal pelo concreto é exercer o pensar de uma forma profícua. Gullar deixa claro isso em seu conto "Verão" de A Estranha Vida Banal. Na experiência do concreto, pondo de lado toda fuga metafísica, toda abstração que, desvinculada do real, nada faz senão afastar o homem da realidade, o homem-poeta 
finalmente encontra seu lugar no mundo e, ao fazê-lo, rejeita quaisquer indagações metafísicas ulteriores sobre a natureza:

AQUI ESTOU, neste esplendente dia de verão, reduzido ao meu corpo. Sem passado, sem sonho, sem fuga. Presente em minhas unhas, em minha pele, em meus cabelos [...] pela minha janela, vejo os edifícios e uma árvore próxima cujas folhas começam a amarelecer. Nada perguntamos um ao outro, eu e a árvore. Nos contentamos com isso [...] $O$ mundo hoje não precisa de explicação [...] Não se precisa de chave para abrir o mundo quando ele se dá a nós, escancarado, sem espessura e sem sombras (1989, p. 23-24)

Essas palavras nos remetem à história segundo a qual Heráclito, numa cabana miserável e alimentando uma pequena fogueira, recebe a visita de jovens ricos que, consternados, veem o filósofo em meio a tamanha pobreza. E Heráclito lhes diz: "Aqui também habitam os deuses" (apud Heidegger, 1957, p. 140-1. Cf. Aristóteles. De partibus. Animalium. A 5, 645 a 17). Heráclito sente-se obviamente em casa, perto de sua fogueira, num momento em que o mundo não carece de qualquer explicação e se oferece a ele, o pensador, que nada faz senão alimentar as chamas, como o faria uma criança. Heráclito ali, como um bicho qualquer (um gato, um cachorro) envolto confortavelmente pelo mundo, distante de preocupações e expectativas, reduzido ao instante e ao presente da chama, absolutamente acolhido e tendo encontrado seu lugar devido. Gullar encerra seu conto falando nesse sentido:

E no mais é aquela bandeja com frutas na mesa da sala. Dentro delas também arde uma flama - fresca e alimentícia. São o outro prato da balança solar. Não estão ali para serem pintadas, mas para que o homem as coma. E esse homem, por acaso, sou eu. (1989, p. 24)

As frutas não são para serem pintadas, mas saboreadas, assim como o pensamento deve saborear o real e não pintá-lo, reduzindo-o a uma abstração estática que faz abrir um abismo entre o pensar e o fluir generalizado das coisas, divorciando o homem do mundo e, logo, de si mesmo. Se tudo é cansaço de si, o homem encontra seu repouso constatando esse desfazer-se das coisas e de si mesmo. Finalmente instalandose conscientemente no fluxo, após "procurar a si mesmo", encontra seu lugar reconhecendo e afirmando seu caráter efêmero: "Precárias são as praias dos/ homens/ 
praias/ que morrem na cama com/ o ódio e o/ sexo: perdem-se/ no pó sem voz", diz Gullar no poema “A avenida" de A Luta Corporal (2007, p. 39).

O reconhecimento da própria imersão no fluxo aparece em vários poemas de Ferreira Gullar. Em “Os Jogadores de Damas” (também de A luta Corporal), o poeta nos diz: "Somos arames estendidos no ar de um pátio que ninguém visita/ Vamos, o que sempre há, e não cessa, é o tempo soprando no tempo/ A orelha dobrada sobre o som do mundo" (2007, p. 42). O mundo, gigantesco conjunto de processos, é, com certeza, um lugar solitário; possui, quando visto com olhar atento, a inconfundível propriedade das praias desertas ou dos grandes galpões abandonados, aquele ruído de fundo, como se houvesse uma máquina que mantivesse em funcionamento todo o cenário. Como Ferreira Gullar nos diz em "O Abismo da Verdura", de A Luta Corporal: "O mar lapida os trabalhos de sua solidão" (2007, p. 44). O mundo, como uma máquina, ao mesmo tempo onipresente e distante, cujo funcionamento só percebemos se apurarmos os ouvidos. No Poema Sujo, esse funcionamento da máquina-mundo é explicitado:

\author{
Que dizer da circulação \\ da luz solar \\ arrastando-se no pó debaixo do guarda-roupa \\ entre sapatos? E da circulação \\ dos gatos pela casa \\ dos pombos pela brisa \\ [...] sem falar na própria velocidade \\ que em cada coisa há \\ como os muitos \\ sistemas de açúcar e álcool numa pêra \\ girando \\ todos em diferentes ritmos (que quase \\ se pode ouvir) \\ e compondo a velocidade geral \\ que a pêra é. (2001, p. 60)
}

Assim, em "Bananas Podres", "o mar o mar/ com seus pistões azuis com sua festa/ tem a ver tem a ver/ com estas bananas/ onde a tarde apodrece feito uma/ carniça vegetal que atrai abelhas/ varejeiras" (2007, p. 155). O poeta apura assim seus ouvidos para captar esses ruídos, esses barulhos, que em cada coisa denunciam o mundo como processo, "pois - como diz Ferreira Gullar em "Nasce o poeta", de Muitas Vozes, nada se basta contente de si” (2007, p. 207). 
Reconhecer-se no fluxo, reconhecer-se efêmero, é reconhecer o próprio caráter mortal e refletir sobre ele. Gullar, quanto a isso, nos fala em "O abismo da Verdura": "a nossa pele já se estende, velha, entre um campo áspero de esferas. Fora, é o jardim, o sol, o nosso reino" (2007, p. 44). Nosso reino é solar, é cotidiano, são essas coisas que nos envolvem, como "a mesa, o jarro, as flores, as paredes, o relógio, a lâmpada, o retrato, os livros, o mata-borrão, os sapatos, as gravatas, as camisas, os lenços" (de "Ocorrência" - 2007, p. 54). Em Ferreira Gullar são frequentes essas enumerações de objetos concretos, que, nos envolvendo no cotidiano, se refletem em nossa alma, acabando por perfazer também nosso cenário interno. Em “Homem Comum”, de Dentro da Noite Veloz, o poeta nos diz: "Sou um homem comum/ de carne e de memória/ de osso e esquecimento [...] Sou como você/ feito de coisas lembradas/ e esquecidas" (2007, p. 78).

A memória é habitada, constituída por esses reflexos, esses estilhaços da concretude (cf. "Memória", de Dentro da Noite Veloz -2007, p. 98). Essa concretude do cotidiano, na qual o homem se encontra e devaneia, é a própria riqueza humana. $\mathrm{O}$ homem, quando liberto de ideias metafísicas que o fazem mortificado e morto para esse mundo, encontra no cotidiano seu tesouro e sua identidade.

Essa dimensão existencial humana, via de regra desprezada pela intelectualidade metafísica e religiosa como sendo menor que as ilusões abstratas, é tudo que o homem realmente possui e experimenta. Há armadilhas metafísicas que é preciso evitar para alcançar uma plena fruição do mundo. No poema "No mundo há muitas armadilhas", de Dentro da Noite Veloz, o poeta reflete sobre isso: "A vida é pouca/ a vida é louca/ mas não há senão ela/ [...] O homem está preso à vida e precisa viver/ o homem tem fome/ e precisa comer/ o homem tem filhos/ e precisa criá-los/ Há muitas armadilhas no mundo e é preciso quebrá-las" (2007, p. 73). Ao evitar essas armadilhas da metafísica, que afastam o homem de seu lugar no mundo, o homem-poeta reencontra-se no mundo e declara seu amor à concretude da qual faz parte. Diz-nos Ferreira Gullar em "Maio 1964”, de Dentro da Noite Veloz: “Amo/ a vida/ que é cheia de crianças, de flores/ e mulheres, a vida/ esse direito de estar no mundo,/ ter dois pés e mãos, uma cara/ e a fome de tudo, a esperança [...] Estou aqui e não estarei, um dia,/ em parte alguma" (2007, p. 81). E prossegue em "Dois e dois: quatro", de Dentro da Noite Veloz: "Como dois e dois são quatro/ sei que a vida vale a pena/ embora o pão seja caro/ e a liberdade 
pequena" (2007, p. 83). Essa consciência aguda da transitoriedade de tudo é expressa em poemas como "Praia do Caju", de Dentro da Noite Veloz, onde o poeta nos lembra: "Escuta:/ o que passou passou/ e não há força/ capaz de mudar isso/ [...] O que passou passou/ jamais acenderás de novo/ o lume/ do tempo que apagou” (2007, p. 87). Em "No Corpo", também de Dentro da Noite Veloz, o poeta declara: "A poesia é o presente" (2007, p. 119). Esse presente, pelo que discutimos acima, é o próprio cotidiano, essas coisas que brilham e se apagam e não voltam mais, aparentemente pequenas, se comparadas às abstrações metafísicas em seu gigantismo vazio.

Esse entorno, a parte que nos cabe no mundo, que nos penetra, nos atravessa, acabando por nos constituir, não depende de nós, fato que nos é absolutamente perceptível quando experienciamos a morte de outro, em especial a morte de um ente querido. Ferreira Gullar nos fala sobre isso no poema "Morte de Clarice Lispector", de Na vertigem do Dia: "Enquanto te enterravam no cemitério judeu/ [...] o táxi corria comigo à borda da Lagoa/[...]/ $\mathrm{E}$ as pedras e as nuvens e as árvores/ no vento/ mostravam alegremente/ que não dependem de nós" (2007, p. 153).

Essa concepção com certeza não visa ser um lenitivo para os que temem a morte, pelo contrário: seu sentido é justamente apagar toda e qualquer ilusão e, colocando o homem frente a frente com a iminência de seu fim, fazê-lo viver plenamente. No poema "Despedida", de Barulhos, o poeta nos diz: "Eu deixarei o mundo com fúria/ Não importa o que aparentemente aconteça./ se docemente me retiro/ [...] Não chorarei./ Não há soluço maior que despedir-se da vida" (2007, p. 173). E, acrescenta Gullar, no poema “Quem sou eu?”, do mesmo livro: “Tudo o que sobrará de mim/ é papel impresso/ [...] mas que é isso/ em comparação com meu corpo real? Meu/ corpo/ onde a alegria é possível” (2007, p. 178). E segue Gullar, no mesmo poema, refletindo sobre essa perda fatal que é despedir-se para sempre da concretude do cotidiano e da possibilidade de saboreá-lo:

Como dizer então: pouco

Me importa a morte?

E sobretudo se existem as histórias em quadrinhos

E os programas de televisão

Que continuarão a passar noite após noite

No recesso dos lares

Numa terça-feira que antecede à quarta-feira numa quinta-feira que antecede à sexta

Ou num sábado 


\title{
Ou num domingo \\ Como dizer \\ Pouca me importa? \\ (2007, p. 178)
}

Essa reflexão escapou aos gregos e romanos que tantos argumentos criaram para tentar nos tirar o medo da morte. Não se trata propriamente de um medo, mas de desgosto por se perder no nada, por nos desligarmos dessa constelação de coisas comuns que nos encantam e nos envolvem, essas concretudes que experienciamos e que, como pano de fundo de nossa existência, sem saber amamos e necessitamos, como a água que em geral só valorizamos quando nos falta. Essas coisas que povoam nossa estranha vida banal, mas que muitas vezes não saborearemos por causa de nossas preocupações, medos, expectativas, acabam por se mostrar a matéria real das coisas e o essencial de nossa vida. Coisas como provar um pão quentinho com manteiga e café ao amanhecer, como abrir a janela e sentir uma brisa e o ruído de automóveis ao longe, como desfrutar a beleza da moça que passa, como tocar um piano na sala de uma casa nas serras de Petrópolis numa noite de inverno. No mesmo livro, no poema "Perda", tratando poeticamente da morte de Mário Pedrosa, o poeta nos diz: "E penso: quantas manhãs virão ainda na história da Terra?/ É perda demais para um simples homem" (2007, p. 181). Pensar que eventualmente jamais há de se voltar "ao ruidoso mundo da vida" (verso de "Fim”, de Muitas Vozes - 2007, p.236) é terrível, trágico. Mas, tornando à dialética, heracliticamente o poeta encaixa a morte no fluxo piroclástico do real. No mesmo livro, no poema "Redundâncias", ele reflete:

\author{
Ter medo da morte \\ é coisa dos vivos \\ o morto está livre \\ de tudo o que é vida \\ Ter apego ao mundo \\ é coisa dos vivos \\ para o morto não há \\ (não houve) \\ raios rios risos \\ E ninguém vive a morte \\ quer morto quer vivo \\ mera noção que existe \\ só enquanto existo \\ (2007, p. 237)
}


Ferreira Gullar assimila heraclitamente a morte como o contrário da vida, que, como o poeta nos diz em "Nova Concepção da Morte", de Muitas Vozes, nos vem "do fundo do corpo, onde a morte mora/ ou dizendo melhor, onde ela circula/ como a eletricidade ou o medo, na medula/ dos ossos e em cada enzima, que veicula,/ no processo da vida, esse contrário: a morte” (2007, p. 245). Então, novamente, como antídoto para a morte, só resta ao homem viver plenamente, concretamente. "A morte diz-nos o poeta em "Tato", de Muitas Vozes, "A morte é uma certeza invencível/ mas o tato me dá/ a consistente realidade/ de minha presença no mundo" (2007, p. 250).

\section{REFERÊNCIAS BIBLIOGRÁFICAS:}

FERREIRA GULLAR. Melhores Poemas. São Paulo: Global, 2007.

FERREIRA GULLAR. Vanguarda e Subdesenvolvimento. $2^{\text {a }}$ ed. Rio de Janeiro:

Civilização Brasileira, 1978.

FERREIRA GULAR. A Estranha Vida Banal. Rio de Janeiro: José Olímpio, 1989.

FERREIRA GULLAR. Poema Sujo. 9a ed. Rio de Janeiro: José Olímpio, 2001.

HEIDEGGER, M. Lettre sur l'Humanisme. Trad. Roger Munier. Paris: Aubier, 1957.

KIRK, RAVEN. Os Filósofos Pré-socráticos. Lisboa: Calouste Gulbenkian. $4^{\mathrm{a}}$ Ed. 1994. 